tuado um grande esforço para corresponder a um tipo de prova difícil para a sua formação académica. O resultado muito positivo compensou o esforço: cada uma das equipas conseguiu uma medalha de prata! Será de destacar que este resultado só foi alcançado pelo trabalho dos alunos, pelo ensino que thes foi ministrado nas suas escolas e pela preparação adicional que lhes foi ministrada, na qual as sociedades científicas tiveram um papel determinante, conjuntamente com os professores das escolas dos alunos.

Em linhas gerais, podemos dizer que os trabalhos decorreram de acordo com o programa previsto, havendo atividades culturais e/ou desportivas organizadas especificamente para os estudantes nos dias em que estes não estavam envolvidos na competição e os mentores estavam envolvidos nos trabalhos de discussão, tradução e correção dos testes. Foram programadas igualmente atividades culturais para os mentores e atividades conjuntas para mentores e alunos.

De referir, por ser o primeiro ano que se realizou, o evento internacional que ocorreu na noite de 24 de abril, no qual cada país, para além de pre-

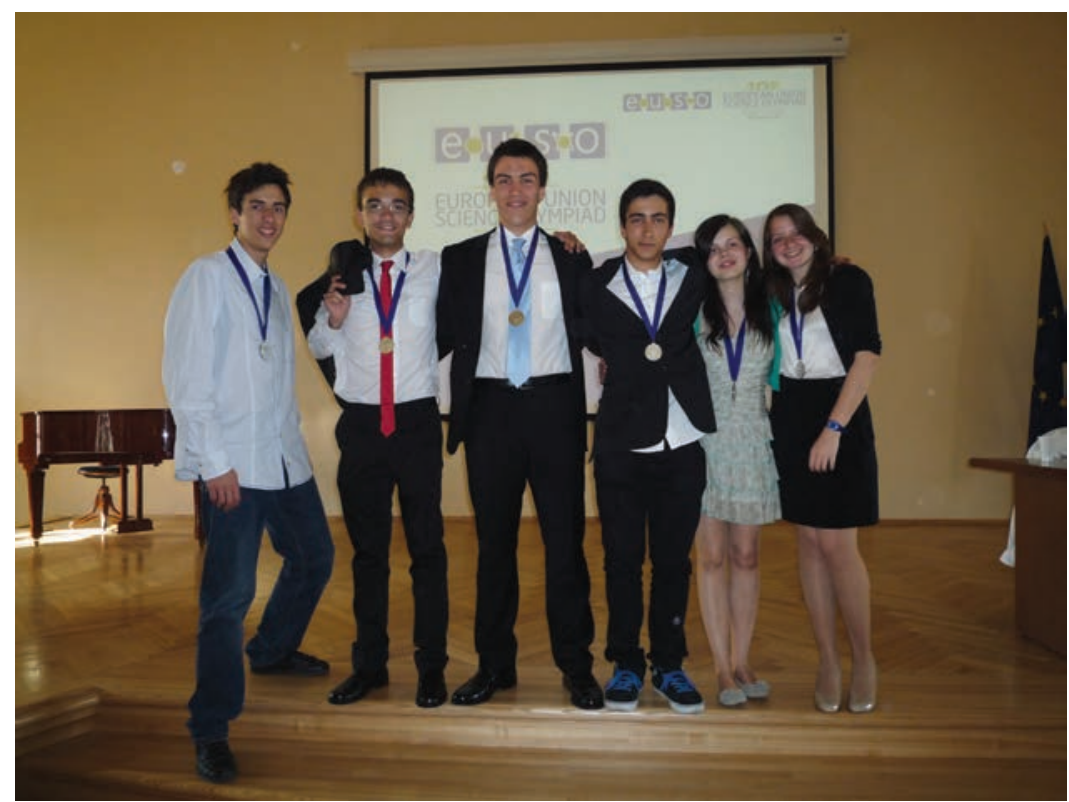

Equipas portuguesas (agraciadas com medalhas de prata) participantes na EUSO2012, na cerimónia de encerramento

parar uma mesa com comida tradicional, teve que fazer uma apresentação salientando os aspetos mais relevantes da sua identidade. Neste evento estiveram presentes embaixadores de vários países, designadamente da Áustria, da República Checa, da Alemanha, da Hungria e da Irlanda.

A participação de Portugal na EUSO 2012 traduziu-se numa experiência muito enriquecedora para todos os participantes, com um regresso a Portugal de ânimo elevado por um justificado orgulho do desempenho.

\section{Isaura Vieira e Maria das Dores Ribeiro da Silva (mdsilva@fc.up.pt)}

Acompanhantes da equipa portuguesa

\title{
Fase Regional de Bragança das Olimpíadas de Química 2013
}

Decorreu no dia 31 de janeiro de 2013, na Escola Superior de Tecnologia e Gestão do Instituto Politécnico de Bragança (IPB), a oitava edição da Fase Regional de Bragança das Olimpíadas de Química+. A organização do evento coube, uma vez mais, ao Departamento de Tecnologia Química e Biológica em colaboração com a Sociedade Portuguesa de Química (SPQ). Este ano a prova laboratorial incidiu na determinação da percentagem de hipoclorito de sódio numa lixívia comercial.

Estiveram em prova um total de 63 alunos distribuídos por 21 equipas provenientes de 5 escolas do distrito, nomeadamente Colégio Torre Dona Chama, Escola ES/3 Emídio Garcia de Bragança, Escola EB2,3/S de Macedo de Cavaleiros, Escola Secundá- ria Miguel Torga de Bragança e Escola Secundária/3 de Mirandela. No final da prestação, todos os alunos e professores acompanhantes almoçaram na cantina do IPB, após o que regressaram ao auditório para a sessão de divulgação de resultados.

No seguimento de anos anteriores, foram atribuídos certificados de participação a todos os alunos e professores, bem como os desejados prémios atribuídos às 3 melhores equipas e às 3 melhores escolas. Para entregar o prémio "Crédito Agrícola" às 3 melhores equipas, correspondendo à abertura de uma conta na Caixa de Crédito Agrícola Mútuo no valor de $100 €, 75 €$ e $50 €$ para cada um dos alunos das equipas que ficaram, respetivamente, na $1 .^{a}, 2 .^{a}$ e $3 .^{a}$ posições, esteve presente a Dra. Carla Pimentel Dias.
As equipas que arrebataram as três primeiras posições, e como tal receberam o prémio "Crédito Agrícola", foram as seguintes:

\section{Medalha de Ouro}

Escola: Escola Secundária/3 de Mirandela

Professores acompanhantes:

Marília Vinhais e Matilde Coroado

Equipa: David Pires Martins, Francisco Caçador e José Guilherme Matos

\section{Medalha de Prata}

Escola: Escola EB2,3/S de Macedo de Cavaleiros

Professor acompanhante:

Nuno Calisto

Equipa: Alexandra Sousa, Joel Pires, João Pedro Carvalho 


\section{Medalha de Bronze}

Escola: Escola EB2,3/S de Macedo de Cavaleiros

Professor acompanhante:

Nuno Calisto

Equipa: Ana Rita Marcos, Daniela Fernandes, Diogo Magalhães

As 3 escolas melhor classificadas foram premiadas com o financiamento da sua participação na Semifinal do Porto das Olimpíadas de Química+, financiamento este que inclui os gastos com a deslocação (patrocínio da Câmara Municipal de Bragança) e alojamento das equipas (patrocínio do Crédito Agrícola). Este ano foi muita a emoção no momento do anúncio da escola classificada no $3 .^{\circ}$ lugar, já que se tratou de uma estreia! No que respeita à classificação escolas, ficaram classificadas em $1 .^{\circ}, 2 .^{\circ}$ e $3 .^{\circ}$ lugares, respetivamente, a Escola Secundária/3 de Mirandela, a Escola EB2,3/S de Macedo de Cavaleiros e o Colégio Torre Dona Chama.

Novamente, e mesmo em "tempos de crise económica", este evento contou com o já habitual e indispensável patrocínio monetário do Crédito Agrí- cola e com o apoio da Câmara Municipal de Bragança na deslocação à Semifinal do Porto, pelo que deixamos uma palavra especial de agradecimento a ambos os patrocinadores, o nosso Muito obrigada por continuarem a fazer possível a realização desta "festa da química" que se vive no dia das provas da Fase Regional de Bragança das $\mathrm{OQ}+$.

Joana Amaral (jamaral@ipb.pt)

Coordenadora da Fase Regional de Bragança das $\mathrm{OQ}^{+}$
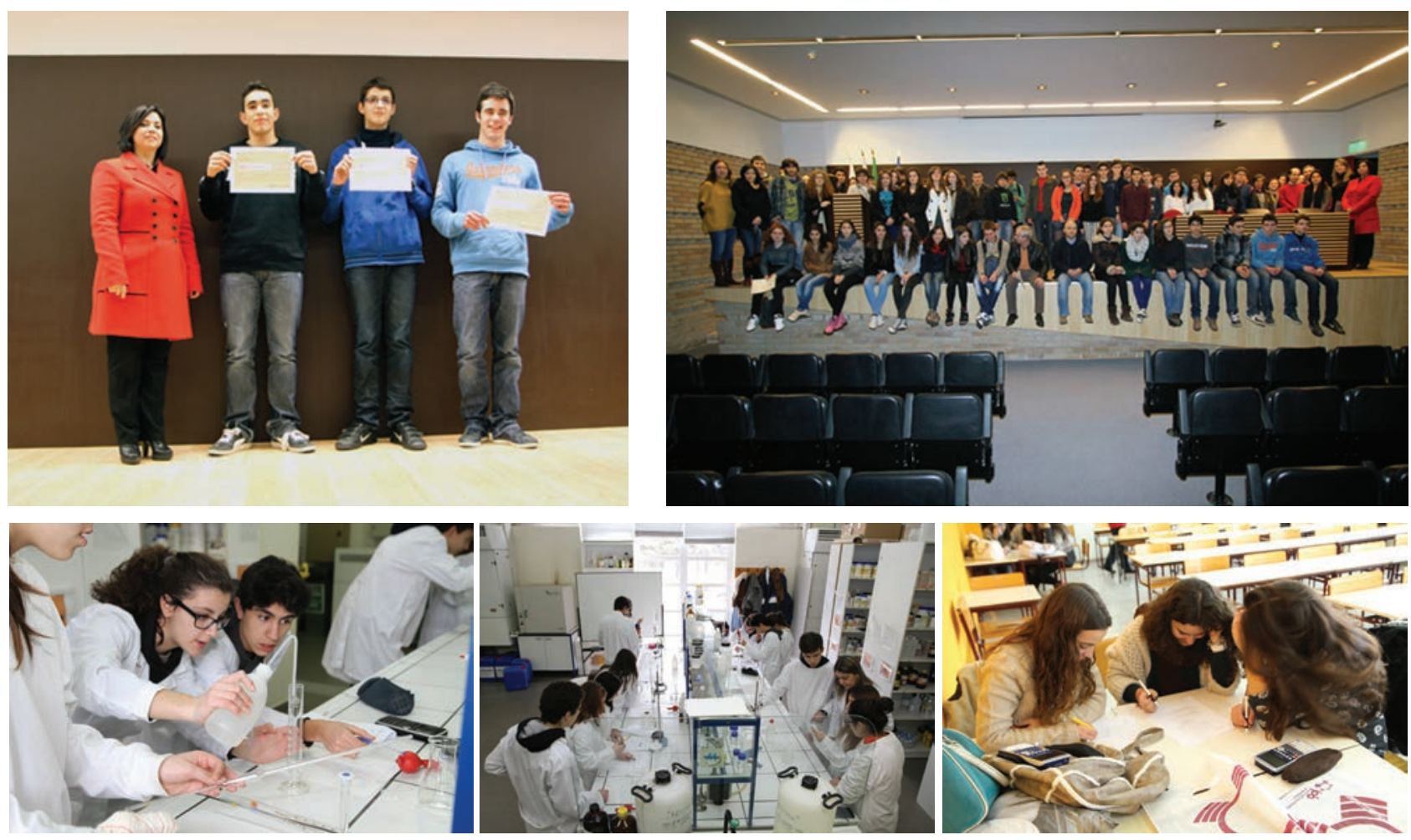

Fotografias do ambiente vivido nas provas. Em cima, à esquerda, equipa classificada em $1 .^{\circ}$ lugar

\section{Assembleia Geral da EuCheMS em 2012}

A Assembleia Geral da EuCheMS decorreu nos dias 11 e 12 de outubro de 2012, no Instituto de Química em Dublin, Irlanda, tendo reunido representantes das diversas Sociedades membro da EuCheMS e outras organizações associadas, representantes das Divisões, Grupos de Trabalho e do Conselho Executivo da EuCheMS e da Rede Europeia de Jovens Químicos, entre outros. Ulrich Schubert presidiu a Assembleia Geral, tendo dado início à reunião informando os parti- cipantes sobre as atualizações mais recentes relativas aos objetivos estratégicos da EuCheMS. Livia Simon Sarkadi, Nineta Majcen e Cristina Todasca complementaram a sua apresentação com atualizações sobre as atividades levadas a cabo nas áreas científicas das Divisões e Grupos de Trabalho da EuCheMS, entre outras.

A reunião contou ainda com dois painéis de discussão: "What are the European needs of member societies?" e "Combining forces for Horizon2020". As apresentações proferidas no âmbito desta reunião podem ser consultadas em http://www.euchems.eu/ about/general-assembly/2012-dublin-ireland/presentations-ga-2012.html.

(adaptado de EuCheMS newsletter, fevereiro de 2013)

Joana Amaral (bquimica@ipb.pt) www.spq.pt 